\title{
Statistical model for economic damage from pluvial floods in Japan using rainfall data and socioeconomic parameters
}

\author{
Rajan Bhattarai $^{1,2}$, Kei Yoshimura ${ }^{1}$, Shinta Seto ${ }^{3}$, Shinichiro Nakamura ${ }^{4}$, and Taikan Oki ${ }^{5}$ \\ ${ }^{1}$ Atmosphere and Ocean Research Institute, The University of Tokyo, 5-1-5, Kashiwano-ha, Kashiwashi, \\ Chiba, 277-8564, Japan \\ ${ }^{2}$ Department of Irrigation, Government of Nepal, Jawalakhel, Lalitpur, Nepal \\ ${ }^{3}$ Graduate School of Engineering, Nagasaki University, 1-14 Bukyomachi, Nagasaki, Japan \\ ${ }^{4}$ Graduate School of Engineering, Nagoya University, Furo-cho, Chikusa-ku, Nagoya, 464-8603, Japan \\ ${ }^{5}$ Institute of Industrial Science, The University of Tokyo, 4-6-1 Komaba, Meguro-ku, Tokyo, Japan \\ Correspondence to: Rajan Bhattarai (raj.basista@gmail.com)
}

Received: 15 September 2015 - Published in Nat. Hazards Earth Syst. Sci. Discuss.: 8 October 2015

Revised: 20 March 2016 - Accepted: 8 April 2016 - Published: 10 May 2016

\begin{abstract}
The assessment of flood risk is important for policymakers to evaluate damage and for disaster preparation. Large population densities and high property concentration make cities more vulnerable to floods and having higher absolute damage per year. A number of major cities in the world suffer from flood inundation damage every year. In Japan, approximately USD 1 billion in damage occurs annually due to pluvial floods only. The amount of damage was typically large in large cities, but regions with lower population density tended to have more damage per capita. Our statistical approach gives the probability of damage following every daily rainfall event and thereby the annual damage as a function of rainfall, population density, topographical slope and gross domestic product. Our results for Japan show reasonable agreement with area-averaged annual damage for the period 1993-2009. We report a damage occurrence probability function and a damage cost function for pluvial flood damage, which makes this method flexible for use in future scenarios and also capable of being expanded to different regions.
\end{abstract}

\section{Introduction}

The assessment of the available water resources and their temporal and spatial distribution, as well as the analysis of flood and drought risk, are of great importance for the health of societies and environmental systems (Lehner et al., 2006).
A world bank report (Dilley et al., 2005) recorded that earthquakes, floods and drought-like natural hazards continue to cause tens of thousands of deaths, hundreds to thousands of injuries and billions of dollars in economic loss every year around the world. Flooding is one of the major causes of physical loss in the world and is continually increasing in trend. Globally, flood damage had increased from an average USD 7 billion per year in the 1980s to more than USD 20 billion per year at the end of 2000s (Kundzewicz et al., 2013). $35 \%$ of physical loss over the past 40 years in the Asia-Pacific region were due to flooding (Asian Development Bank, 2013). Moreover, occurrence of floods was the most frequent of all natural disasters (Jha et al., 2011). Recent large-scale and record-breaking flooding events in terms of physical loss caused world leaders and policymakers to pay serious attention to proper planning and management of flood control infrastructure and the formulation of future adaptation strategies. China, in 2010, experienced the largest flood damage of USD 51 billion in one single year and the 2011 flood in Thailand caused the most expensive insurance loss ever, worldwide, with total liability estimated at around USD 15 billion (Kundzewicz et al., 2013). Flooding events in Germany and central Europe in May and June 2013 were the most expensive, costing around USD 16 billion (Wake, 2013). Economic loss due to floods is higher in developed countries, whereas the economic loss expressed as a proportion of gross domestic product is much higher in developing countries (Handmer et al., 2012). Even though a huge invest- 
ment in the improvement of flood control infrastructures has been made, flooding remains a serious problem throughout the Europe (Kundzewicz et al., 2013) and the case of Japan is also similar. Annual expenditure for flood control in the government budget in Japan is nearly USD 10 billion (about JPY 1 trillion) as reported in Kazama et al. (2009). The high potential of flood damage in Japan is basically due to the fact that approximately $9 \%$ of its land is flood-prone, but contains $41 \%$ of population and $65 \%$ of the national assets (Kundzewicz et al., 2013).

Flooding related to rainfall is usually divided into largescale floods due to high discharge of rivers and streams (fluvial flood), and local or urban floods that occur due to excessive rainfall that overwhelms local drainage capacity (Pluvial flood) (Bouwer, 2013). Even though published flood damage events were often from fluvial flooding, the share of pluvial flooding cannot be underestimated. Pluvial flood damage, particularly in densely populated urban areas and in areas with poor drainage facilities, was recorded to be very high not only during heavy rainfall but also during moderate to low rainfall events. Rapid urbanization with inadequate engineered inner-city drainage infrastructures increases the damage, not only to the economy but also to human lives (Kundzewicz et al., 2013). The Ministry of Land, Infrastructure, Transport and Tourism (MLIT) of Japan had shown that $86 \%$ of total economic flood damage in the Tokyo metropolitan during 1998-2007 was only due to pluvial floods (MLIT, 2008b). The flood damage in Kochi in September 1998 (Yamamoto et al., 1999) was largely due to pluvial floods, and the failure of inner drainage systems also led to the higher flood damage in the 2000 Tokai flood (Ikeda et al., 2007). Average annual economic damage to residential property attributable to pluvial floods in Japan was approximately USD 1 billion (JPY 100 billion) (about $45 \%$ of annual flood damage of the same kind) during 19932009 (MLIT, 2009). Figure 1 shows the historical total national fluvial and pluvial flood damage to general property in Japan. Here, general property implies housing, household appliances, depreciable business properties, business inventory properties, depreciable agriculture/fisheries and agriculture/fisheries inventory property. The figure reveals that annually, pluvial floods causes significant damage, and efforts for pluvial flood damage control seem ineffective. Even a well-prepared city in terms of flood defence infrastructures, like Tokyo, suffers frequent pluvial flood damage. Rapid urbanization with an ageing population, a decline in preparedness of local communities to fight flood disaster and an increase in new exposed facilities make cities more vulnerable than before (Ikeda et al., 2007). Smaller cities and towns are typically more severely affected by pluvial floods, perhaps due to less-developed flood defences, as pluvial flood damage per capita in those areas was reported to be higher than in bigger cities. Pluvial flood impacts on the UK and many European cities were also recorded as very high in recent years (Morris et al., 2009; Van Riel, 2011; Spekkers et al., 2013).

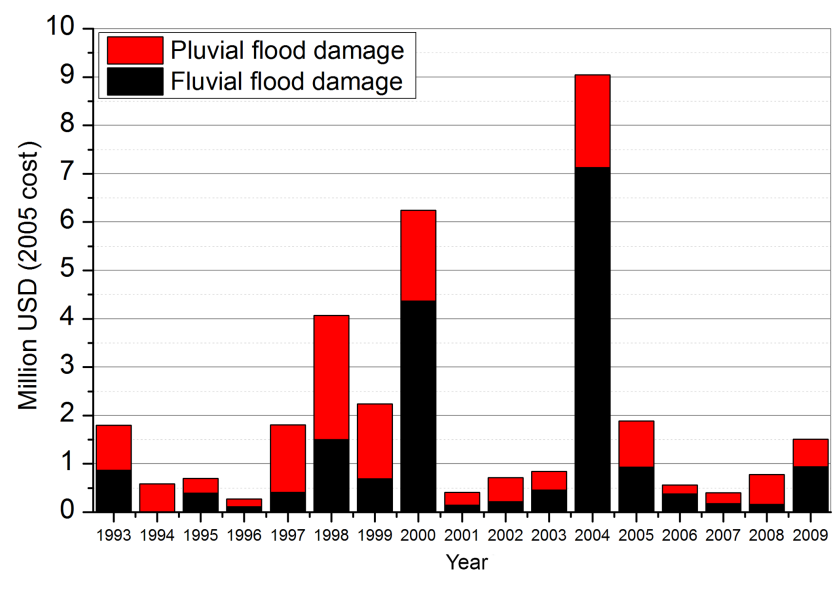

Figure 1. Historical general property damage due to pluvial and fluvial floods in Japan for the period 1993-2009. The fluvial flood damage shows its high fluctuation annually; however pluvial flood damage is much more constant over the period.

The scenarios in the present warn us for the future as well, since small changes in rainfall intensity can lead to a rapid increase in loss in urban areas due to the highest concentration of capital (Bouwer, 2013; Morita, 2011; Zhou et al., 2012). Pluvial floods seem very serious and contribute to high physical loss all over the world; however, relatively few studies have been reported on this issue for present and also future climate (Seneviratne et al., 2012).

In regard to the above discussion, a proper way of assessing pluvial flood damage amount for each hazard event on a local to a global scale for the present and the future is a demanding task for scientific communities. An accurate estimate of economic damage is now indispensable for decision makers so that economic viability of proposed infrastructure development, mitigation and/or adaptation plans for flood defence can be justified and can be used in overall flood risk management strategies (Lavell et al., 2012; Merz et al., 2010).

A wide range of methodologies have been developed and applied for assessing flood damage risk over the last few years; however most of these models were developed for fluvial flooding. A diverse approach has been applied for flood risk assessment by many researchers and organizations. Many conceptual models which provided the different vulnerability or risk indices for spatial comparison were developed for a local to global scale. Some popularly known indices are event-based disaster risk index (DRI) (UNDP, 2004), hazard index for megacities (HIM) (Munich Re, 2004), prevalent vulnerability index (PVI) (Cardona, 2007), discharge probability index (DPI) (Yoshimura et al., 2008), flood vulnerability index (FVI) (Hara et al., 2009) and advance flood risk index (AFRI) (Okazawa et al., 2011). Each index has their own criteria and spatial resolution (local to global scale) for calculating indices for risk or vulnerabilities. This index-based approach might be suitable for assess- 
ing relative risk distribution; however as discussed earlier, a decision maker requires an absolute damage amount in monetary terms so that economic viability of a proposed infrastructure development plan for flood defence can be justified.

The direct flood damage estimating models developed so far have basically utilized two different submodels: first, to evaluate hydrological parameters (e.g. flood velocity, flood duration and flood depth), based on some physically based hydrologic modelling techniques (hydrological models), and second, to evaluate absolute/relative damage amount based on a susceptibility function usually derived from empirical analysis (loss models), which relates the hydrological parameters to damage amount. The basic features of hydrological models are to estimate hydrological parameters for a hazard event generally defined by its exceedance probability (return period). On the other hand, a loss model is a central idea for flood damage estimation (Merz et al., 2004) and the most common way of estimating direct damage amount is the use of depth-damage functions often termed as a susceptibility function or a vulnerability function (Dutta et al., 2003; Glade, 2003; ICPR, 2001; Jongman et al., 2012a; Kazama et al., 2009; Kelman and Spence, 2004; Kreibich et al., 2010; Rodda, 2005; Schmidt-Thomé et al., 2006; Smith, 1994; Ward et al., 2013). Some loss models are multi-parameter models based on several hazard parameters (flood depth, flow velocity, contamination etc.) and resistance parameters (flood-prone object type and/or size, mitigation measures etc.) for example, HAZUS-MH (FEMA, 2003), multi-coloured manual model (Penning-Rowsell et al., 2005), FLEMOps (Apel et al., 2009) and FLEMOcs (Kreibich et al., 2010).

Flood damage assessment methodology and their results further depend on the defined spatial boundary (Apel et al., 2009). To date, several studies have been done from a very local municipal level (Baddiley, 2003; Grünthal et al., 2006), catchment scale (Dutta et al., 2003, 2006; ICPR, 2001), national scale (Hall et al., 2005; Kazama et al., 2009; Rodda, 2005) and regional scale (Schmidt-Thomé et al., 2006) to the global scale (Jongman et al., 2012b; Ward et al., 2013). Winsemius et al. (2013) also provided a framework for global river flood risk assessment. Due to the increasing need for national-scale and even larger scale flood damage assessment (Winsemius et al., 2013), macro-scale studies are getting much popular.

Most of the damage assessment models that have been discussed so far were primarily developed for fluvial flooding; however, the loss model could be a common component for both fluvial and pluvial flood damage assessment. A few studies on pluvial floods and their associated damage have also been reported. Zhou et al. (2012) described a framework for economic pluvial flood risk assessment considering future climate change which quantifies flood risk in monetary terms as expected annual damage in different return periods of rainfall. Escuder-Bueno et al. (2012) presented a methodology for assessing pluvial flood risk using two different curves, one for societal risk and the other for economic risk; however both were limited to a local scale.

The flood damage assessment models to date contain a number of uncertainties in both hydrological and loss models. Hydrological models possess uncertainties regarding extreme value statistics used, stationary and homogeneity of data series, consideration of physical properties (e.g. dikes and drainage systems) of a location, and calibration and validation of model output etc. (Apel et al., 2009). However, the largest sources of uncertainties in damage modelling were associated with prescribed depth-damage functions (Apel et al., 2009; Hall et al., 2005; Jongman et al., 2012a; Merz et al., 2004, 2010; de Moel and Aerts, 2010). A reason for uncertainty in loss models is their crude assumption of the relationship between damage and flood depth only in most cases. Moreover, these models were generally developed for some specific location using past flood records and their validation are always a critical issue for their temporal and spatial transferability. Uncertainty related with the property types and their values is also critical in many cases. There is still a need for better understanding of different processes leading to damage so that they can be modelled appropriately (Meyer et al., 2013). A special report of the Intergovernmental Panel on Climate Change (IPCC), often called IPCC SREX (IPCC, 2012), also focused on the need for more empirical and conceptual efforts to develop robust damage assessment methodology.

In regard to the present situation, this study is motivated towards a development of a simple but robust statistical model as integral of hazard, vulnerability and exposure, based on a historical database in Japan for pluvial flood damage assessment, that could be used for all regions irrespective of their individual characteristics of pluvial flooding. Moreover, the model described in this paper overcomes several uncertainties regarding both hydrological and vulnerability models and is capable for estimating total annual damage on a national scale in simple and rapid way. Our method for damage assessment is a macro-level statistical model that focuses on pluvial floods and considers all daily precipitation events in a year, thereby calculating annual damage. In this study, each daily rainfall event is characterized by its exceedance probability based on the Gumbel distribution. We report two different functions, namely, the damage occurrence probability function and the damage cost function. The former represents the relationship of exceedance probability of rainfall and its corresponding damage probability, and the latter represents the relationship of exceedance probability of rainfall and relative damage cost of a particular location. These two functions were further used to calculate annual damage and thereby average annual damage (AAD) for the whole of Japan due to pluvial flooding. We also examined uncertainties associated with daily damage data and their preparation. A popular bootstrap method was applied for uncertainty analysis. Sensitivity tests were also performed to examine robustness of the model. We believe this model helps 
decision makers to estimate annual damage for short-term planning and to estimate average annual damage for longterm planning with a reasonable level of confidence. As a macro-level study, we use readily available data, including population density, elevation and national annual gross domestic product (GDP), which make this method more flexible for use in future climate scenarios and also make it extendable to global assessment. The next section describes the methodology, including forcing data and theory. The subsequent section presents the results for annual damage, along with uncertainty analysis. The final section concludes the paper.

\section{Methodology}

\subsection{Data}

\subsubsection{Precipitation data}

Daily precipitation data were used as an external forcing for hazard in this study since they are a strong external loading for pluvial floods (Zhou et al., 2012). Daily precipitation data were obtained from the Auto Meteorological Data Acquisition System (AMeDAS), which cover all areas of Japan at an interval of about $20 \mathrm{~km}$ on average. High density of observation stations and having longer observation periods led us to use the AMeDAS data set. Daily precipitation data for the period 1976-2009 were utilized. Approximately 1300 Japan Meteorological Agency (JMA) rain gauges were sampled, and data were interpolated using the inverse distance method for its simplicity and its appropriateness for a relatively dense gauge network (Dirks et al., 1998; Mouri et al., 2013; Yoshimura et al., 2008) to assign a value to each grid point in a $0.1^{\circ} \times 0.1^{\circ}$ grid. For each $0.1^{\circ}$, the surrounding rain gauges were averaged with a weighting of $1 / d^{2}$, where $d$ is the distance from the centre of the grid to the rain gauge. Similarly, precipitation of spatial resolution 20 and $60 \mathrm{~km}$ was prepared for sensitivity analysis due to input forcing of different horizontal resolution. The annual maximum daily precipitation data were computed from daily precipitation data for each grid, thereby calculating the exceedance probability of annual maximum daily rainfall, which will be explained later.

\subsubsection{Population density data}

The population size of a location has a strong influence on flood risk (Kundzewicz et al., 2013). Increasing population in a flood-prone zone increases exposure; and therefore total damage amount increases with increasing population (de Moel et al., 2011; Morita, 2011). The case of Japan is even more serious as a large number of the population live in a relatively small flood-prone area (Kundzewicz et al., 2013). However, population size is not a sole component for determining flood risk. Residents of small cities or towns are often far more vulnerable to disaster than residents of megacities (Cross, 2001). Three population density classes (low: 0-250 persons per $\mathrm{km}^{2}$, medium: 250-2000 persons per $\mathrm{km}^{2}$ and high: $>2000$ persons per $\mathrm{km}^{2}$ ) were prepared after many trials to analyse the damage occurrence probability and vulnerability in different population densities. Obviously the adopted population density classes gave the best model output during both the calibration and the validation period. For this purpose, annual population data for 19932009 were used from the Gridded Population of the World, version 3 (GPWv3), and these data were interpolated onto a $0.1^{\circ} \times 0.1^{\circ}$ grid. The global data were adjusted based on the Japan national census so that the population of each prefecture was properly given. The prefectural population data were taken from the Statistics Bureau, Ministry of Internal Affairs and Communications (MIC), government of Japan.

\subsubsection{Damage data}

Damage data are always a critical issue in flood damage assessment. A lack of reliable, consistent and comparable data is a major obstacle (Hall et al., 2005; Handmer, 2003; Handmer et al., 2012; Kundzewicz et al., 2013; Merz et al., 2010; Meyer et al., 2013) to formulating a robust methodology and to validating it. Moreover, the level of uncertainty in damage estimation is mainly dependent on available data (Escuder-Bueno et al., 2012; Handmer, 2003). Several international flood damage databases which archive the flood damage data from all over the world along with duration (start and end date) and location exist, for example EM-DAT, Dartmouth flood observatory, Munich Re and Swiss Re etc. Since all databases have their own criteria of damage recording, local-scale little damage (Meyer et al., 2013), and in some cases great damage, was often not recorded because the total annual damage recorded in these database was much smaller than that recorded in respective national damage databases. However, such national-level damage databases are only available for a few developed countries. In this study, daily damage data due to pluvial floods for the period 19932009 based on economic damage to tangible general property (housing, household appliances, depreciable business property, business inventory property, depreciable agriculture/fisheries property, agriculture/fisheries inventory property) from MLIT's flood disaster statistics were used. The various characteristics of this database are well described in Mouri et al. (2013). These data include the name of the city or town where a disaster happened, the type of disaster (fluvial or pluvial), the type of damaged assets, the start and end date of flooding, and the total amount of damage. Further disaggregation of these data into temporal and spatial resolution was a really big challenge. For this study, the first day of damage onset was considered the damage day and the total recorded damage amount was assigned to that single day. These damage data were further interpolated onto the $0.1^{\circ} \times 0.1^{\circ}$ grid based on the geometric centre of the 
city (Mouri et al., 2013; Yoshimura et al., 2008). The geometric centre of each city was calculated using an addressmatching service developed by the Centre for Spatial Information Science, the University of Tokyo (CSIS UT, 2013). Obviously, the above assumptions for the spatial and temporal breakdown of damage data produce some uncertainties. Yoshimura et al. (2008) examined the various criteria of spatial and temporal breakdown of the recorded damage data and found that the above consideration works better for simulating daily damage amount for Japan. Better damage data recording techniques for both spatial and temporal scale are indispensable for developing a robust damage model. Nevertheless, area-averaged annual national damage was well calculated by the proposed methodology, showing its performance capability.

\subsubsection{Gross domestic product (GDP) data}

Assets value is another important component of economic damage assessment. Current models for economic flood damage estimation possess high uncertainty regarding the assets value used (Jongman et al., 2012a; de Moel and Aerts, 2010). For regionalization of a model, the integrated asset value, which has a uniform definition for all regions, is essential. For a macro-scale study, an aggregated asset value is more appropriate to make it flexible for expanding to other regions (Merz et al., 2010) and in the absence of real assets data in present situation, GDP can be a powerful candidate in this regard (Jongman et al., 2012a). The proposed model was also developed in view of its application on a global scale in which GDP could be a very useful indicator for asset value. In this study, GDP data were used as an asset value, and macro-economic vulnerability is defined as the ratio of damage to GDP at a location, which will be described more in a later section. National annual GDP data for 1993-2009 were taken from the International Monetary Fund (IMF) world economic outlook database of April 2012. Prefectural GDP data were taken from the Statistics Bureau, Ministry of Internal Affairs and Communications (MIC), government of Japan. These data, shown in Fig. 2, reveal that the GDP of each prefecture is approximately proportional to the population (these data are for 2003, but the trend was similar in other years). The national-level annual GDP was hence distributed onto each grid proportional to the grid population (Chan et al., 1998; Jongman et al., 2012b; Ward et al., 2013) as given in Eq. (1):

$\mathrm{GDP}_{\text {grid }}=\mathrm{GDP}_{\text {nation }} \cdot \frac{\text { Population }_{\text {grid }}}{\text { Population }_{\text {nation }}}$.

\subsubsection{Slope data}

Many geological and topographical characteristics contribute to the flood risk (Kundzewicz et al., 2013). The topographical characteristic fundamentally determines the flooding ex-

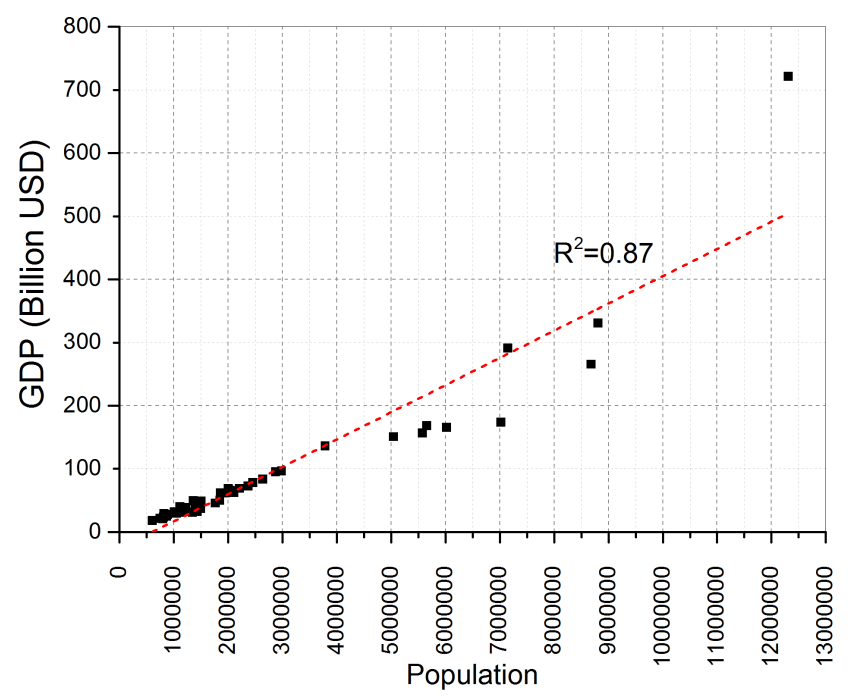

Figure 2. GDP as a function of prefectural population in Japan for the year 2003. The data show that the population-GDP relation follows a linear fit except in a few cases.

tent, its depth and velocity, which ultimately govern flooding impact at a location. In most of the reported methodology (Dutta et al., 2003; Kazama et al., 2009; Zhou et al., 2012), the topographical slope was implicitly used in their hydrological models. In some models, direct elevation data were used to estimate flood water depth, for example in Feyen et al. (2012). We also evaluated the topographical dependency in damage occurrence at a location. To preserve the impact of topographical characteristics in flooding, we used the slope as one of the parameters in our damage occurrence probability function, the details of which will be described later. Topographical slope data were prepared based on GTOPO30 data sets (USGS, 1996). GTOPO30 is a global digital elevation model (DEM) with horizontal grid spacing of 30 arcsec (approximately $1 \mathrm{~km}$ ). The maximum slope at each grid point was compared with the slope in the surrounding eight grids, and the mean of the maximum slopes in each grid was used for the $0.1^{\circ}$ grid data. To test sensitivity of DEM data in model output, slope data were also prepared using 3 arcsec Shuttle Rader Topography Mission digital elevation model (SRTM3) data set following the process described above.

\subsection{Theory}

\subsubsection{General definition of flood risk}

Extreme events interacting with exposed human resources and economic activities can lead to disaster. To this end, various definition of risk can be found in different literatures. Smith (1996) defined the risk simply as a probability of a specific hazard occurrence. Davidson and Shah (1997) further elaborated the risk as a product of hazard, exposure, vulnerability, capacity and measures. Hall et al. (2005) specifically 
defined flood risk as the product of the probability of flooding and the consequential damage, summed over all possible flood events. As per the definition of United Nation International Strategy for Disaster Reduction (UNISDR) (UNISDR, 2009), disaster risk is a product of hazard, vulnerability and exposure, and hence can be simply written as

Risk $=$ Hazard $\cdot$ Vulnerability $\cdot$ Exposure.

IPCC (2012) broadly defined the disaster risk as the likelihood over a specified time period of severe alternations in the normal functioning of a community or society due to hazardous physical events interacting with vulnerable social conditions, leading to widespread adverse human, material, economic or environmental effects that require immediate emergency response to satisfy critical human needs and that may require external support for recovery. In fact, the definition of risk is still not clear and often controversial (Okazawa et al., 2011). In this study, we define damage risk as a product of disaster occurrence probability and corresponding vulnerability due to a hazard event at a location. Vulnerability is defined as the conditional relative damage amount with respect to the GDP (assets) and termed as the damage cost function. Figure 3 shows the conceptual framework for the different components and their interrelationship for damage assessment in this study. Here, the damage risk can simply be written as

$$
\begin{aligned}
\text { Damage risk }= & \text { Damage occurrence probability } \\
& \cdot \text { Damage cost function. }
\end{aligned}
$$

Daily rainfall data were characterized by their exceedance probability. In general, an exceedance probability is a probability that an event of specified magnitude will be equalled or exceeded in any defined period of time, on average and generally calculated and expressed as once a year. These exceedance probabilities are further related with the probability of damage occurrence at a location on the one hand (referred to as the damage occurrence probability), and the average cost of damage due to this event on the other hand (referred ad damage cost function). Flooding and flood damage are two different phenomena (Mouri et al., 2013), and hence to understand flooding and its associated damage better, we defined flood damage occurrence probability and damage cost function separately. The division of total damage risk into two components helped us to judge the contributing factors (exposure and susceptibility) of damage risk by defining each risk component independently. The probable cost of damage was then obtained with the product of these two components. The calculation procedures of each component are described in the following subsections.

\subsubsection{Exceedance probability of rainfall $(w)$}

Annual maximum daily rainfall was assumed to follow a two-parameter Gumbel distribution. The annual maximum

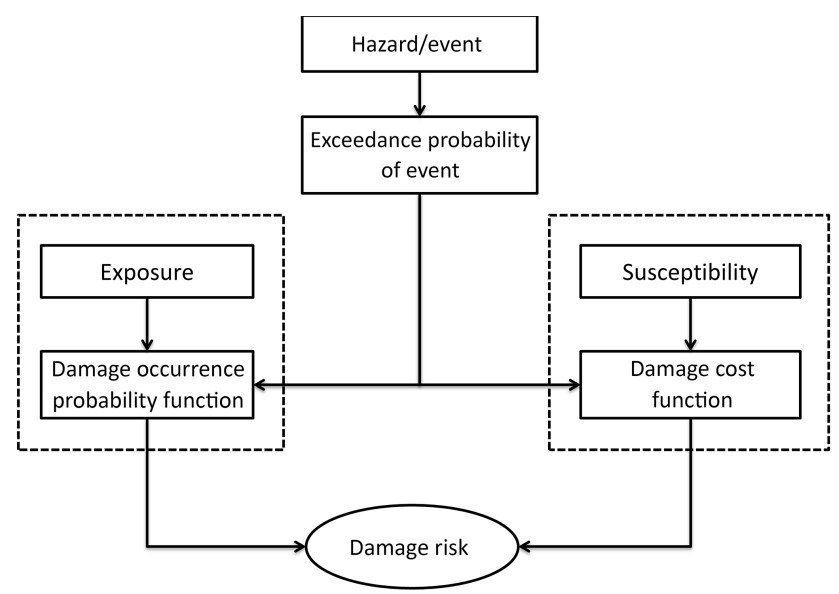

Figure 3. Different components of damage assessment and their interrelationships. Damage occurrence probability appears to be more dependent on exposure, whereas damage cost seems to be dependent on susceptibility in a particular location.

daily rainfall data for the period 1976-2009 were used to calculate the Gumbel parameters. Gumbel distribution is one of the extreme value statistical distributions which has widely been adapted for hydrological events (Hirabayashi et al., 2013; Mouri et al., 2013; Ward et al., 2013; Yoshimura et al., 2008). Mouri et al. (2013) showed the applicability of Gumbel distribution for AMeDAS daily precipitation for the whole of Japan using a standard least-squares criterion. We also evaluated the goodness of fit of the Gumbel distribution to annual maximum daily rainfall using the probability plot correlation coefficient (PPCC) (Hirabayashi et al., 2013; Vogel, 1986) test, which revealed that about $94 \%$ grids have a PPCC value greater than the critical PPCC $(0.95532$ for 34 samples), corresponding to $5 \%$ significance level, proving its applicability. Based on the Gumbel distribution extreme value theory, the cumulative distribution function for the annual maximum daily precipitation, $x$, can be written as

$F(x)=e^{-\exp (-a(x-b))}$,

where $a$ and $b$ are the Gumbel parameters, calculated based on the annual maximum daily precipitation value from the 34-year (1976-2009) precipitation data set for each grid point using a method of moments. The parameter $a$ is a scale parameter, and was calculated from

$a=\frac{\sqrt{6} \pi}{6 \sigma}$,

where $\sigma$ is the standard deviation of the annual maximum daily precipitation rate. The parameter $b$ is a location parameter and was calculated from

$b=\mu-\frac{0.5772}{a}$,

where $\mu$ is the mean annual maximum daily precipitation rate, and 0.5772 is Euler's constant. The exceedance prob- 

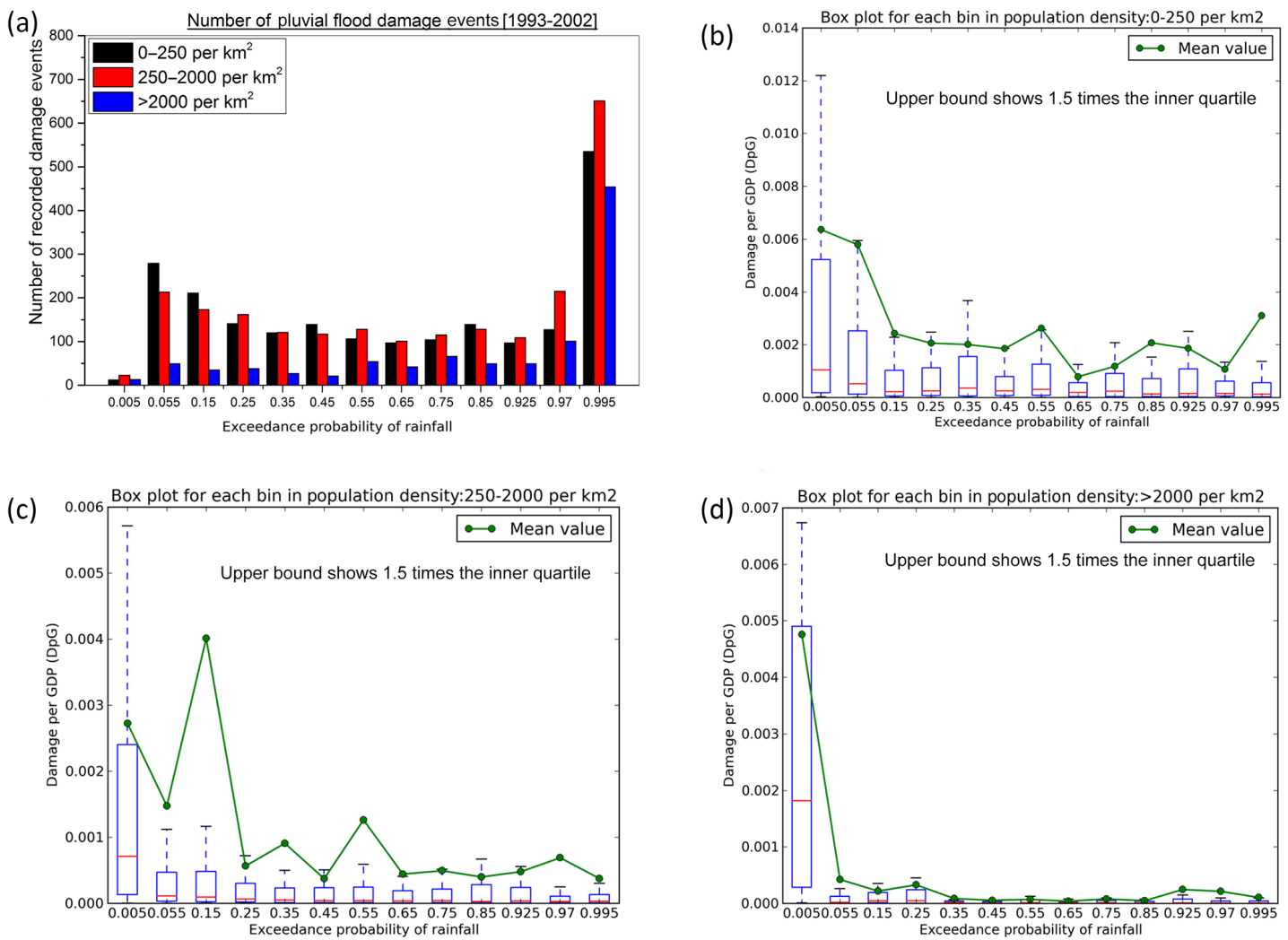

Figure 4. (a) Number of total recorded damage events in each exceedance probability bin and distribution of DpG in each exceedance probability bin for (b) low population density class, (c) medium population density class and (d) high population density class. The number of damage events was in higher exceedance probability bins in all three population density classes as seen in (a). However, the amount of damage was associated with lower exceedance probability bins as seen in (b), (c) and (d).

ability of each daily precipitation can be defined as

$w=1-F(x)$.

In this study, all daily rainfall was characterized by its exceedance probability using Eq. (7); hence each grid possesses a different amount of daily rainfall with the same return period. Defining rainfall by its exceedance probability gives comparable values among the different grids.

\subsubsection{Damage occurrence probability (DOP)}

The damage occurrence probability (DOP) is the probability of damage at a given location (i.e. grid point) in response to a rainfall event. To calculate damage occurrence probability at each location, some "bins" of exceedance probability were prepared. The width of each bin was fixed as per its sensitivity regarding the number of daily rainfall events and the number of damage events. Several trials were performed to fix the bin size, especially for lower exceedance probability bins. The number of damage events for each bin for all three population density classes is shown in Fig. 4a. The figure reveals that the number of damage events was very low in smaller exceedance probability bins (i.e. higher return period); however the number of damage events in higher exceedance probability bins (i.e. smaller return period) was surprisingly higher. The damage events in frequent rainfall events were often neglected in previous damage modelling techniques, although this damage could have a considerable share in the total damage amount. The DOP was calculated as a ratio of damage events $(n)$ in relation to the total number of events $(N)$ within a specified exceedance probability bin using recorded damage data as in relation (8) below.

$\mathrm{DOP}=\frac{n}{N}$

Three population density classes (low: 0-250 per $\mathrm{km}^{2}$, medium: 250-2000 per km² and high: $>2000$ per $\mathrm{km}^{2}$ ) were set up to evaluate the dependency of population density on damage occurrence probability at a location due to daily rainfall events using Eq. (8). The recorded damage in each grid for the years 1993-2002 was used to calculate damage occurrence probability. As seen in Fig. 4a, the exceedance probability bin of 0-0.01 (large return period) obviously had a smaller number of events, thereby a smaller number of damage events. Only 12 (out of 120 events), 23 (out of 56 events) and 13 (out of 19 events) damage events were recorded in this bin for the low, medium and high population density 
class respectively. The damage occurrence probability as a function of exceedance probability of daily rainfall for all three population density classes is shown in Fig. 5. The figure shows that areas with higher population density had a higher damage occurrence probability than lower populated areas. The figure clearly shows the dependency of damage occurrence probability on the exposure of the location. Since topographical slopes have a strong influence on drainage of water from a location and can contribute to pluvial flooding, the relationship of damage occurrence probability and topographical slopes was also analysed for all population density classes based on the damage recording data for the period 1993-2002 in each grid. For this, at least three topographical slope subclasses were set up based on the available data. Different slope subclasses for each population density class were set up to manage the number of damage events. For example, high population density class was subdivided into three slope subclasses: $0-0.5 \%, 0.5-1 \%$ and $1-25 \%$. The smallest exceedance probability bin $(0-0.01)$ containing only 8 (out of 9), 3 (out of 5) and 2 (out of 5) damage events produces a DOP of $0.889,0.600$ and 0.400 respectively. An uncertainty related to a small number of data remains especially for this bin; however the size of the lower exceedance probability bin was optimized, so it produced better results in both the calibration and validation period. Figure 6 shows an example of topographical dependency for high population density class with different slope subclasses. The figure reveals that a lower topographical slope exhibits higher damage occurrence probability, perhaps due to the poor natural drainage of water. For slopes with gradients greater than $25 \%$, no damage was recorded (even in populated areas). We implemented a multi-regression fitting algorithm for the probability of damage as a function of exceedance probability $(w)$ and the topographical slope $(S)$ for different population density classes to produce an equation for damage occurrence probability as given in Eq. (9). For a slope higher than $25 \%$, no probability of damage was presumed.

$$
\left.\begin{array}{ll}
\operatorname{DOP}(w, S)=e^{c \ln \left(\frac{1}{w}-1\right)+d^{*}(S \text { in } \%)+d^{\prime}} & \text { for } S<25 \% \\
\operatorname{DOP}(w, S)=0 & \text { for } S \geq 25 \%
\end{array}\right\}
$$

The parameters $c, d$ and $d^{\prime}$ in the above relationship were computed for all population density classes using damage data for the period 1993-2002 and Eq. (8). The calibration of these parameters was performed to produce the reasonable national annual damage during 1993-2002. The calibrated parameter values are tabulated in Table 1.

\subsubsection{Damage cost function}

The damage cost function describes the degree of damage associated with each daily rainfall event and hence also can be termed as vulnerability. As described earlier, the most common way of estimating direct damage amount so far was the use of a depth-damage function. A depth-damage function shows the relationship between flood depth and rela-

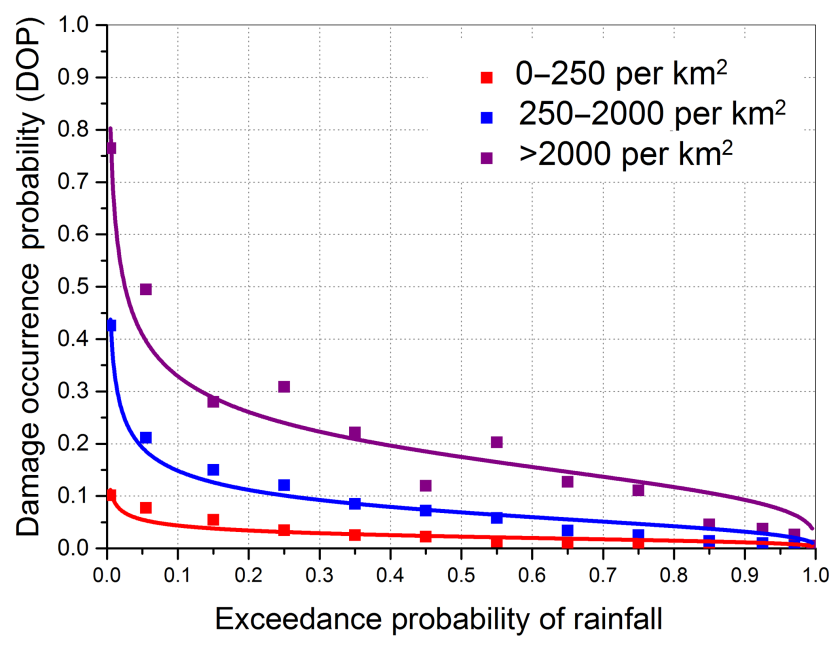

Figure 5. The damage occurrence probability as a function of the exceedance probability of rainfall for different population density classes. Higher population density exhibits higher damage occurrence probability and vice versa.

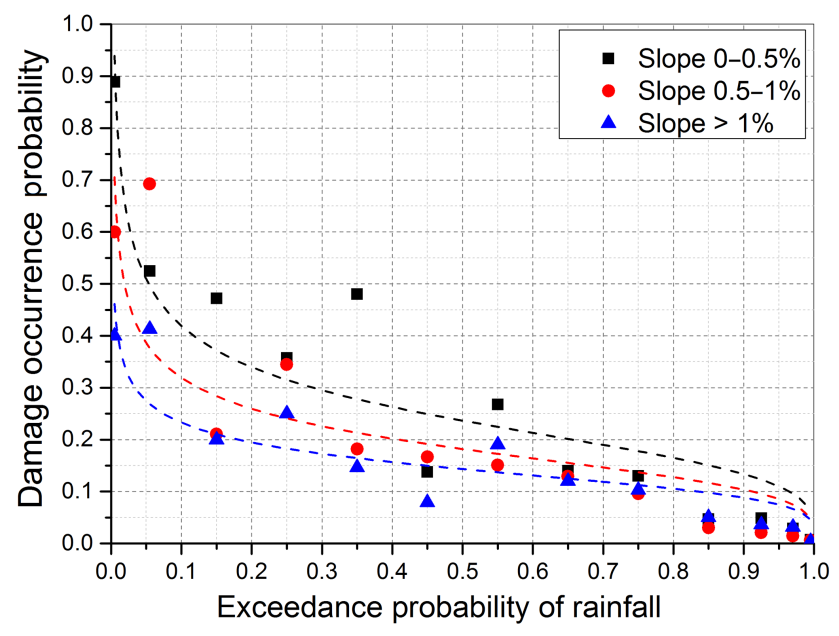

Figure 6. The damage occurrence probability as a function of the exceedance probability of rainfall for different topographical slopes for population density class $>2000$ persons per $\mathrm{km}^{2}$. The lower slopes area shows higher damage occurrence probability than higher slopes.

tive damage associated with it. Total damage amount due to a flood event is not only dependent on water depth but also on other factors like flow velocity, duration of inundation, sediment concentration etc. (Kundzewicz et al., 2013; Merz et al., 2004), resistance parameters (type, size, shape and property of objects) (Kreibich et al., 2010) and the level of preparedness of a society (Merz et al., 2004). Another main issue related to depth-damage functions is their spatial and temporal non-transferability especially for nationallevel and global-level damage assessment, because they were often developed from local municipality scale or catchment 
Table 1. Damage occurrence parameter values for Japan in all three population density classes.

\begin{tabular}{lrcccc}
\hline Population density class & Population density & $c$ & $d$ & $d^{\prime}$ & $R^{2}$ \\
\hline Low & $0-250 \mathrm{~km}^{-2}$ & 0.55 & -0.01100 & -4.1218 & 0.38 \\
Medium & $250-2000 \mathrm{~km}^{-2}$ & 0.52 & -0.01194 & -2.8861 & 0.48 \\
High & $>2000 \mathrm{~km}^{-2}$ & 0.40 & -0.04374 & -1.7125 & 0.42 \\
\hline
\end{tabular}

Table 2. Vulnerability parameters values in Japan for all three population density classes. The 90th (upper) and 10th (lower) percentile values were derived from the means of 10000 bootstrap samples.

\begin{tabular}{|c|c|c|c|c|c|c|c|c|c|c|}
\hline \multirow{2}{*}{$\begin{array}{l}\text { Population } \\
\text { density class }\end{array}$} & \multirow{2}{*}{$\begin{array}{r}\text { Population } \\
\text { density }\end{array}$} & \multicolumn{3}{|c|}{$p$} & \multicolumn{3}{|c|}{$q$} & \multicolumn{3}{|c|}{$R^{2}$} \\
\hline & & Upper & Mean & Lower & Upper & Mean & Lower & Upper & Mean & Lower \\
\hline Low & $0-250 \mathrm{~km}^{-2}$ & 0.002142 & 0.001535 & 0.001000 & 0.311 & 0.295 & 0.241 & 0.56 & 0.56 & 0.47 \\
\hline Medium & $250-2000 \mathrm{~km}^{-2}$ & 0.000769 & 0.000510 & 0.000251 & 0.377 & 0.381 & 0.385 & 0.47 & 0.54 & 0.74 \\
\hline High & $>2000 \mathrm{~km}^{-2}$ & 0.000101 & 0.000070 & 0.000041 & 0.761 & 0.720 & 0.589 & 0.74 & 0.72 & 0.58 \\
\hline
\end{tabular}

scale. Asset values at a location also always create a large uncertainty, which is largely dependent upon various building characteristics. In this study, we introduce a damage cost function that relates the exceedance probability of rainfall to the average damage per GDP $(\mathrm{DpG})$ for each population density class. The GDP was taken as an asset value which indicates the asset, irrespective of the individual characteristics of a location; and hence its applicability to all regions is widened.

In this study, we prepared some exceedance probability bins. Mean DpG in each bin for different damage events was calculated for the period 1993-2002 for all three population density classes. Damage per GDP value showed very large variation within a bin as seen in Fig. 4b, c and d as box plots for low, medium and high population density classes respectively. The lower and higher ends of the box give the 25th and 75th percentile value of the data, whereas red bars within each box show the median value of the data within each bin. Larger deviation in each bin is shown by the whisker plot (dotted line) showing a range of 1.5 times the inner quartile. The green line joins the mean value of $\mathrm{DpG}$ in each bin. The figures (box plots) reveal that there is a large deviation of damage value with respect to its property even with similar hazard events. This large variation is partly due to the bin size itself which constitutes a large variation of hazard frequency, and partly due to the large uncertainty in damage amount, even with the same hazard event at a location. Moreover, the mean value of damage per GDP is significantly higher than its corresponding median value, showing that a low number of damage events causes a larger share in total annual damage. We adopted an inverse power law to relate exceedance probability of rainfall $(w)$ and damage per GDP (DpG) for mean value for each population density class, as given in re- lation (10).

$\mathrm{DpG}=p \cdot w^{-q}$,

where the parameters $p$ and $q$ were computed from historical data (1993-2002) for each population density class with a least-squares fitting technique. The parameters $p$ and $q$ implicitly show the vulnerability variables for all three population density classes. Other dependent factors of vulnerability were not analysed in this study. Further study will be carried out in the direction of assigning vulnerability variables of a location rather than lumped vulnerability parameter values. Figure 7 shows the fitted damage cost function curves for all three population density classes. The vulnerability parameters $p$ and $q$ in Eq. (10) were then estimated for mean DpG as tabulated in Table 2. The uncertainty related to the spatial and temporal averaging of damage per GDP in each exceedance probability bin was evaluated using a bootstrap method and will be described in next section. The damage cost function is a crucial component required to calculate the absolute damage resulting from an event at a given location. This corresponds to the level of damage at a given location for each precipitation event. The damage cost function curves shown in Fig. 7 reveal that lower population density areas lead to greater damage per GDP than in higher population density areas, and show higher vulnerability to pluvial flood damage, perhaps due to fewer flood defence works.

\subsubsection{Uncertainty analysis}

As discussed before, a flood damage assessment model possesses a number of uncertainties which always limit its use for future projection. In this study, damage due to an event was computed using Eqs. (9) and (10). Vulnerability parameters were calculated by fitting a power curve with mean DpG value; however as seen from Fig. $4 b$, c and d, the DpG 


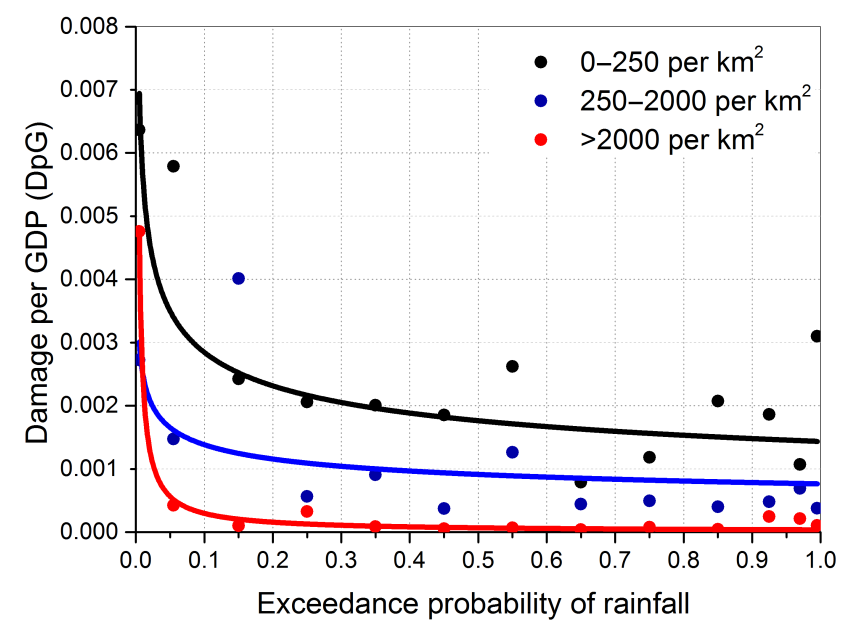

Figure 7. The damage cost function for different population density classes as a function of the exceedance probability of rainfall derived using mean DpG. The vulnerability varies with population density, and a lower populated area exhibits higher vulnerability.

values in each exceedance probability bin have large variation. The uncertainty related to very large variation of $\mathrm{DpG}$ in each bin was evaluated using a bootstrap method (Efron, 1979). Using a bootstrap technique of resampling for the data in each bin, 10000 bootstrap samples were generated and their means were calculated. 10th and 90th percentile values were taken for these mean values (10000 in number), assigning lower and upper uncertainty range of the mean for each bin. The parameter values for Eq. (10) were also calculated for these 10th and 90th percentile DpG along with mean DpG. The values of vulnerability parameter for these two percentile DpG are also tabulated in Table 2 along with computed parameter values for mean DpG. The former two hence gave the maximum and minimum limit of our damage estimation with a probable confidence band of $80 \%$, and the latter one provides the total annual damage.

\subsubsection{Annual damage and average annual damage}

Annual damage was calculated from the sum of the daily damage value due to each rainfall event in a year, which can be given as

annual loss of each grid

$$
=\sum_{1}^{365} \mathrm{DOP}\left(w_{i}, S\right) \cdot \operatorname{DpG}\left(w_{i}\right) \cdot \mathrm{GDP} .
$$

The DOP and DpG (mean) for each rainfall event were calculated using relations (9) and (10) for each grid, and summation of the damage from all daily rainfall events during a year was taken as the annual loss for the grid point as in Eq. (11). The summation of damage from all grids over Japan gave the annual national damage due to pluvial flood inundation. Average annual damage from a period seems to be a more appropriate representative value for a period because of the stochastic nature of damage events. Moreover, use of 90th percentile and 10th percentile DpG from bootstrap means gave the highest and lowest limit of the annual damage, which provides $80 \%$ probable range of the estimated annual damage.

\subsubsection{Calibration and validation}

Parameters in the DOP and the damage cost function were first computed using the damage data for the period 19932002. Damage data for 2003-2009 were used for validation purpose. Only DOP parameters were calibrated during the fine tuning process to estimate better annual damage variation and average annual damage during the periods. The average annual damage and its annual variation were observed while calibrating DOP parameters.

\section{Results}

The results of the proposed model were evaluated according to its capability to produce the annual total national damage and average annual damage in both calibration and validation period using the damage occurrence probability function and the damage cost function with mean DpG. Along with total national damage, total annual damage for all three population density classes was also evaluated. Figure $8 \mathrm{a}, \mathrm{b}$ and c show the annual variation of total calculated damage within low, medium and high population density classes respectively along with the recorded damage variation. The annual variation of total national pluvial flood damage (recorded and calculated) is shown in Fig. 8d. The upper and lower ranges of annual damage were calculated using parameters of damage cost function with 90th and 10th percentile of the means of bootstrap samples, as shown by the shaded area in the figures. Annual variation in the calculated damage compared with the recorded variation in damage shows good agreement in most years, except for 1997 (in low population density class) and 1998 (in medium population density class). As these data were generated using spatial and temporal averaging, the large localized damage in some grids may have been underestimated. For example, the largest recorded damage in 1998 was due to the Kochi flood on 24 September 1998; however, as Iwasada et al. (1999) pointed out, the inundation of the Kochi flood resulted from overflowing water from a part of the Kasumi levee (a traditional Japanese discontinuous levee) along the Kokubu river. It means that this particular inundation was unexpected, given the existing flood mitigation measures. Thus, some of the recorded damage from pluvial flooding may be from river flooding and may therefore be over-recorded.

The annual variation in the total damage during the validation period shows good agreement with the recorded data, 

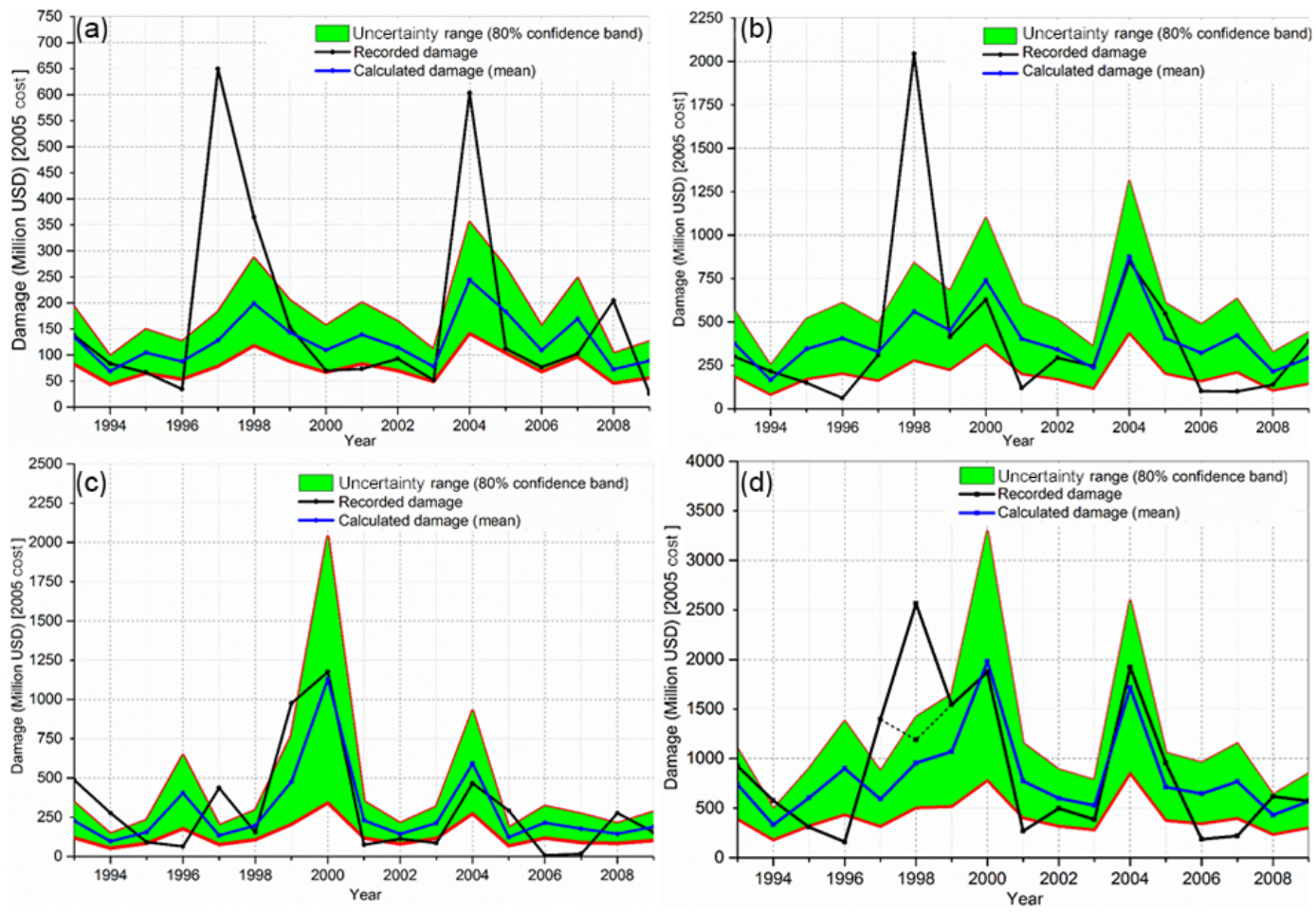

Figure 8. Total annual pluvial flood damage variation in (a) low population density class, (b) medium population density class, (c) high population density class, and (d) whole nation. The period 1993-2002 was used for calibration and 2003-2009 for validation. The dotted line for 1997-1999 in (d) shows the highest recorded damage excluding the Kochi flood in 1998. The shaded area spreads from 10th percentile (lower) to 90th percentile (upper), derived from mean values of 10000 bootstrap samples, which shows the $80 \%$ confidence band of damage estimation using proposed methodology. The data were normalized to 2005 levels.

which may be due to the absence of any event causing extensive damage in this time period in a particular grid.

The computed average annual national damage (with the financial costs normalized to 2005 levels) during the calibration period 1993-2002 was USD 853.92 million, which is slightly lower than the recorded average annual damage over this period (USD 1011.19 million). Computation of the average annual damage for 2003-2009 using this method gave USD 807.09 million, slightly higher than the recorded average damage in this period (USD 744.61 million). Fukubayashi (2012) also estimated the national average annual damage for flood inundation in Japan during 1993-2009 to be USD 980 million, but did not evaluate the annual variation in the damage.

Even though the model was calibrated and validated with bulk national damage data, the performance of the model with different population density classes was also very good, as seen from Fig. 8a, b and c. This led us to present the spatial distribution of the average annual damage and average annual damage per GDP for the period 1993-2009 using Eqs. (9), (10) and (11). The results are shown in Figs. 9 and 10 , respectively. The average annual damage distribution reveals very large damage in big city areas, particularly Tokyo, Osaka, Nagoya and Niigata, which is related to the

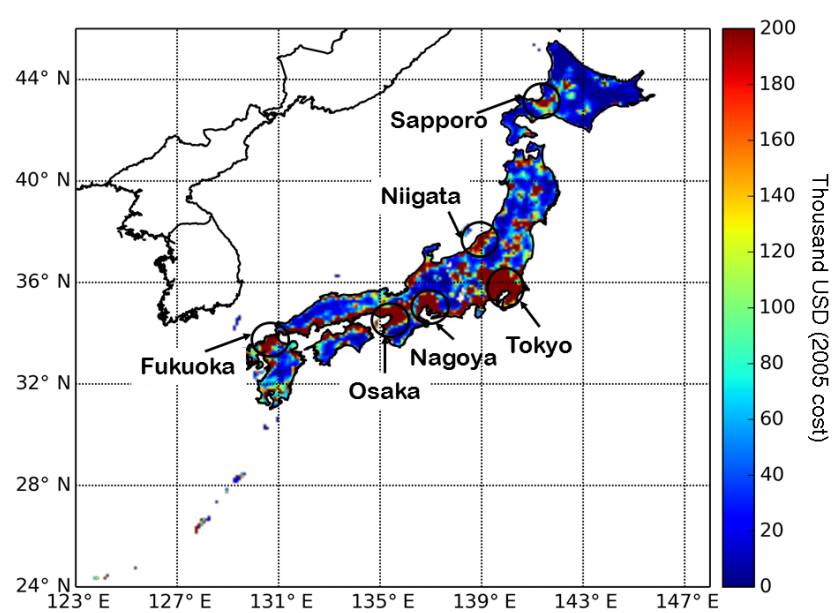

Figure 9. Spatial distribution of average annual damage $0.1^{\circ}$ grid (1993-2009) over Japan. More highly populated areas had higher absolute damage value.

large population density in flatlands. However, the spatial distribution of the average damage per GDP shows an inverse trend. In general, scattered small towns have higher damage 


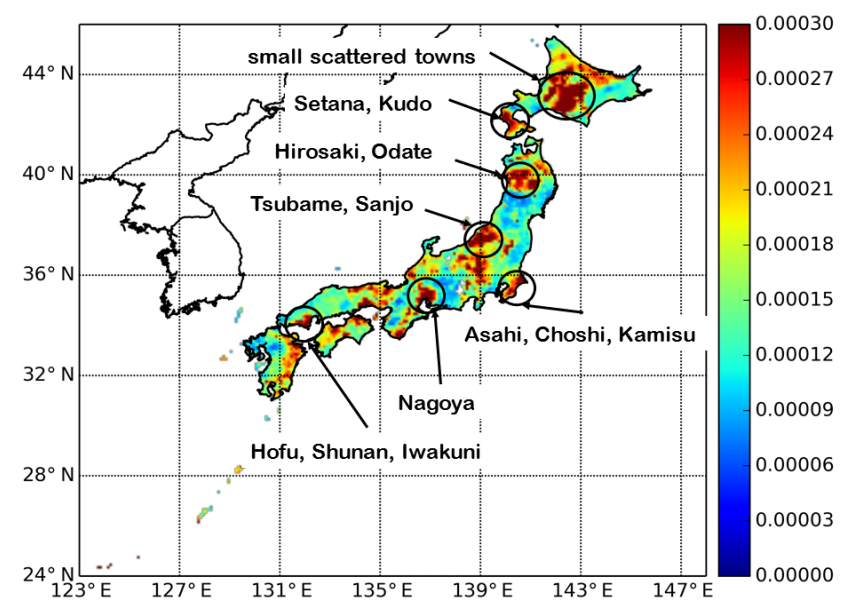

Figure 10. Spatial distribution of average annual damage per GDP per $0.1^{\circ}$ grid for 1993-2009 over Japan. Many areas with smaller population densities exhibited larger damage per GDP.

per GDP than big cities do, perhaps due to less preparation for pluvial flooding.

The sensitivity of model results due to different horizontal resolution precipitation input (AMeDAS) and slope computed from a finer DEM (SRTM3) than the DEM used for model development (GTOPO30) was also evaluated. The annual variation of total national damage due to the use of 20 and $60 \mathrm{~km}$ resolution AMeDAS precipitation data along with $0.1^{\circ}$ data is shown in Fig. 11. The figure reveals that the model is insensitive towards the horizontal resolution of precipitation forcing. This is mainly due to the exceedance probability of rainfall being calculated and used in the model rather than the precipitation amount itself. Figure 12 shows the model results with the slope derived from the SRTM3 DEM and GTOPO30 DEM in which the model was optimized. Since the slope coefficient was optimized with the slope derived from the GTOPO30 DEM, the model output with slope from the finer DEM is lower. It might be due to the fact that the slope derived using the high-resolution DEM is steeper than that of coarser resolution.

A MLIT report (MLIT, 2008a) described a significant increase in the daily precipitation rate in Japan over the last 100 years, as well as increases in short-term heavy rainfall over the past 30 years as also revealed in Utsumi et al. (2011). The report further revealed, based on different studies, that future annual precipitation and summer precipitation will increase in most parts of Japan. This is expected to decrease the return period of an event and thereby increase the probability of damage and the size of the damage for a given event. Practical guidelines for strategic climate change adaptation planning for flood disaster prevention (MLIT, 2010) focuses on three main strategic areas: socioeconomically developed and urbanized areas, alluvial plains and regions where flood control measures are currently underdeveloped. The guidelines also highlight the importance of economic damage as-

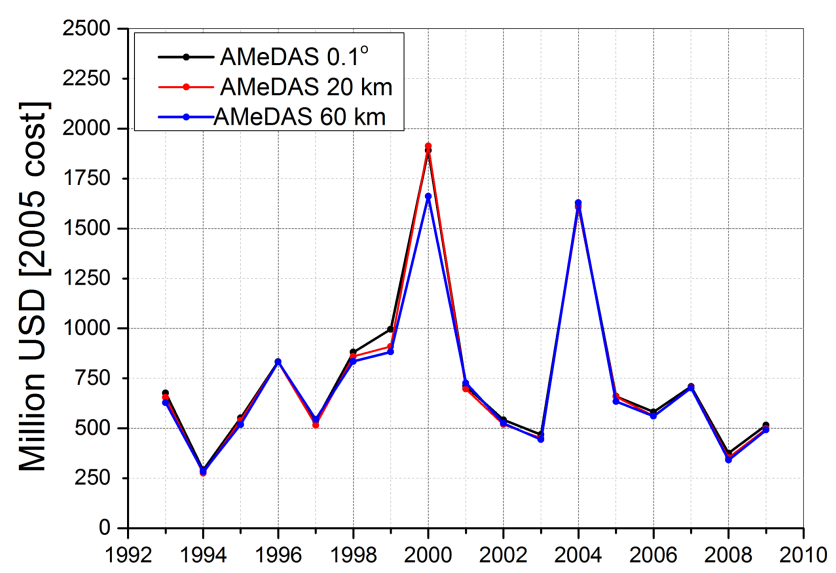

Figure 11. Annual variation of total national annual pluvial flood damage with AMeDAS precipitation forcing with three different horizontal resolutions. Very little discrepancy is seen for precipitation input with different horizontal resolutions.

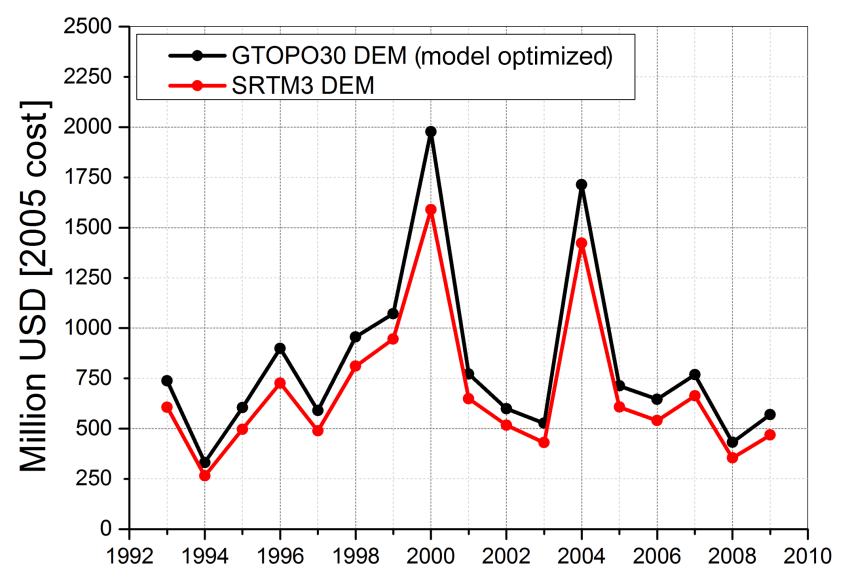

Figure 12. Annual variation of pluvial flood damage with the slope derived from GTOPO30 DEM data, in which the model was optimized, and SRTM3 DEM data. The damage estimation with the slope derived from a finer resolution DEM is lower than that of a coarse-resolution DEM.

sessment. The average annual damage estimation for pluvial floods and its regional distribution could be valuable data for any future adaptation or mitigation planning. We believe that our methodology and results can be applied in such studies.

\section{Discussion and conclusion}

We have described a method to calculate annual pluvial flood damage based on daily precipitation data, and socioeconomic and topographical data. Using this method, we can compute the damage from every event in a year, many of which are typically excluded when computing damage from a low-frequency event only. We observe a significant contribution of high-frequency low-magnitude events in total an- 
nual damage, which is included in this method via the probability of damage. The probability of damage at a given location depends on the population density and the topographical slope of the landscape. The damage occurrence probability is higher for a high population density area because of a high concentration of properties.

The damage cost function curves show that damage per GDP was lower in highly populated areas than in areas of low population density at a given frequency of rainfall events. We believe that the damage per GDP in highly populated urban areas reflects the ability to withstand the disaster. The spatial variation in the total damage cost and the damage per GDP across Japan were computed for each grid point using simple relationships. The rapid and simple way for calculating annual damage and average annual damage due to pluvial floods with some uncertainty will be a very useful tool for decision makers for planning, policymaking, budgeting and the management of urban drainage systems. We believe the damage occurrence probability function and damage cost function will be applicable in addressing future climate and socioeconomic changes and can also be applied to other areas or countries. However a precise optimization of parameters might be needed for other nations. The functions and results presented here also provide some insight into the improvement of the present integrated physical hydrological modelling technique for flood damage assessment which might have the capability to assess flood damage associated with even shorter rainfall duration (subdaily scale), which is now much more difficult to incorporate in the presented model due to the temporal and spatial scale of the present damage recording technique.

Acknowledgements. This study was conducted under the framework of the Precise Impact Assessment on Climate Change of the program for Risk Information on Climate Change (SOUSEI program) supported by the Ministry of Education, Culture, Sports, Science and Technology, Japan (MEXT), RECCA/SALSA project, JSPS KAKENHI, Grant-in-Aid for Scientific Research (S) (23226012), Core Research for Evolutionary Science and Technology (CREST) program from the Japan Science and Technology Agency, and the Environment Research and Technology Development Fund (ERTDF) S-10. The first author was financially supported by the government of Japan through the MEXT scholarship program for $\mathrm{PhD}$ study at the University of Tokyo and the study was also a part of his $\mathrm{PhD}$ dissertation.

Edited by: T. Glade

Reviewed by: two anonymous referees

\section{References}

Apel, H., Aronica, G. T., Kreibich, H., and Thieken, A. H.: Flood risk analyses - how detailed do we need to be?, Nat. Hazards, 49, 79-98, doi:10.1007/s11069-008-9277-8, 2009.
Asian Development Bank: Investing in resilience: Ensuring a disaster-resistant future, Mandaluyong City, Philippines, available at: www.adb.org, last access: 16 October 2013.

Baddiley, P.: The flood risk in Cairns, Nat. Hazards, 30, 155-164, doi:10.1023/A:1026114316844, 2003.

Bouwer, L. M.: Projections of future extreme weather losses under changes in climate and exposure, Risk Anal., 33, 915-930, doi:10.1111/j.1539-6924.2012.01880.x, 2013.

Cardona, O. D.: Indicators of disaster risk and risk management. Program for Latin America and The Caribbean, Washington DC, available at: http://www.iadb.org/exr/disaster/pvi.cfm? language=EN\&parid=4, last access: 17 October 2013, 2007.

Chan, L. S., Chen, Y., Chen, Q., Chen, L., Liu, J., Dong, W., and Shah, H.: Assessment of global seismic loss based on macroeconomic indicators, Nat. Hazards, 17, 269-283, doi:10.1023/A:1008060510137, 1998.

Cross, J. A.: Megacities and small towns?: different perspectives on hazard vulnerability, Global Environmental Change Part B: Environmental Hazards, 3, 63-80, doi:10.1016/S14642867(01)00020-1, 2001.

CSIS UT: Tools and utilities using the position reference technology - Geocoding Tools \& Utilities, available at: http://newspat.csis. u-tokyo.ac.jp/geocode/, last access: 17 October 2013.

Davidson, R. A. and Shah, H. C.: An Urban Earthquake Diaster Risk Index, The John A. Blume Earthquake Engineering Center, Standford, California, Report No. 121, 1997.

de Moel, H. and Aerts, J. C. J. H.: Effect of uncertainty in land use, damage models and inundation depth on flood damage estimates, Nat. Hazards, 58, 407-425, doi:10.1007/s11069-0109675-6, 2010.

de Moel, H., Aerts, J. C. J. H., and Koomen, E.: Development of flood exposure in the Netherlands during the 20th and 21st century, Global Environ. Chang., 21, 620-627, 2011.

Dilley, M., Chen, R. S., Deichmann, U., Lerner-Lam, A. L., Arnold, M., Agwe, J., Buys, P., Kjkstad, O., Lyon, B., and Yetman, G.: Natural Disaster Hotspots: A Global Risk Analysis-Synthesis Report, Washington DC, 2005.

Dirks, K. N., Hay, J. E., Stow, C. D., and Harris, D.: High-resolution studies of rainfall on Norfolk Island Part II?: Interpolation of rainfall data, J. Hydrol., 208, 187-193, 1998.

Dutta, D., Herath, S., and Musiake, K.: A mathematical model for flood loss estimation, J. Hydrol., 277, 24-49, doi:10.1016/S0022-1694(03)00084-2, 2003.

Dutta, D., Herath, S., and Musiake, K.: An application of a flood risk analysis system for impact analysis of a flood control plan in a river basin, Hydrol. Process., 20, 1365-1384, doi:10.1002/hyp.6092, 2006.

Efron, B.: Bootstrap Methods: Another Look at the Jackknife, Ann. Stat., 7, 1-26, 1979.

Escuder-Bueno, I., Castillo-Rodríguez, J. T., Zechner, S., Jöbstl, C., Perales-Momparler, S., and Petaccia, G.: A quantitative flood risk analysis methodology for urban areas with integration of social research data, Nat. Hazards Earth Syst. Sci., 12, 2843-2863, doi:10.5194/nhess-12-2843-2012, 2012.

FEMA: HAZUS: Multi-hazard loss estimation model methodology, Washington DC, 2003.

Feyen, L., Dankers, R., Katalin, B., Peter, S., and Barredo, J. I.: Fluvial flood risk in Europe in present and future climates, Climatic Change, 112, 47-62, doi:10.1007/s10584-011-0339-7, 2012. 
Fukubayashi, N.: Probability of Water-Related Disaster Occurrence and Risk Evaluation in Japan, Master thesis, The University of Tokyo, Japan, 2012.

Glade, T.: Vulnerability assessment in landslide risk analysis, DieErde, 134, 123-146, 2003.

Grünthal, G., Thieken, A. H., Schwarz, J., Radtke, K. S., Smolka, A., and Merz, B.: Comparative Risk Assessments for the City of Cologne - Storms, Floods, Earthquakes, Nat. Hazards, 38, 2144, doi:10.1007/s11069-005-8598-0, 2006.

Hall, J. W., Sayers, P. B., and Dawson, R. J.: National-scale Assessment of Current and Future Flood Risk in England and Wales, Nat. Hazards, 36, 147-164, doi:10.1007/s11069-0044546-7, 2005.

Handmer, J.: The chimera of precision?: Inherent uncertainties in disaster loss assessment, Australian Journal of Emergency Management (AJEM), 18, 88-97, 2003.

Handmer J., Honda, Y., Kundzewics, N., Arnell, N., Benito, G., Hatfield, J., Mohamed, I., Peduzzi, P., Wu, S., Sherstyukov, B., Takahashi, K., and Yan, Z.: Changes in impacts of climate extremes: human systems and ecosystems, in: Managing the Risks of Extreme Events and Disasters to Advance Climate Change Adaptation. A Special Report of Working Groups I and II of the Intergovernmental Panel on Climate Change (IPCC), Cambridge University Press, Cambridge, UK, and New York, NY, USA, 231290, 2012

Hara, Y., Umemura, K., Kato, K., Connor, R., and Sato, Y.: The development of flood vulnerability index applied to 114 major river basin around the world, Journal of Japan Society of Hydrology and Water Resources, 22, 10-23, 2009.

Hirabayashi, Y., Mahendran, R., Koirala, S., Konoshima, L., Yamazaki, D., Watanabe, S., Kim, H., and Kanae, S.: Global flood risk under climate change, Nature Climate Change, 3, 816-821, doi:10.1038/nclimate1911, 2013.

ICPR: Atlas on the risk of flooding and potential damage due to extreme floods of the Rhine, Koblenz, Germany, 2001.

Ikeda, S., Sato, T., and Fukuzono, T.: Towards an integrated management framework for emerging disaster risks in Japan, Nat. Hazards, 44, 267-280, doi:10.1007/s11069-007-9124-3, 2007.

IPCC: Managing the Risks of Extreme Events and Disasters to Advance Climate Change Adaptation, A Special Report of Working Groups I and II of the IPCC, edited by: Field, C. B., Barros, V., Stocker, T. F., and Dahe, Q., Cambridge University Press, Cambrige University Press, Cambridge, UK, and New York, NY, USA, 2012.

Iwasada, M., Sasaki, K., and Murakami, M.: The damage of river structure and natural bank protection in Kochi flood disaster in 1998, Shikoku-based affiliate of Japan Society of Civil Engineers, Takamatsu, Shikoku, Japan, 128-129, 1999.

Jha, A. K., Bloch, R., and Lamond, J.: Cities and Flooding: A guide to integrated urban flood risk management for the 21 st century-A summary for policy makers, Washington DC, available at: www. worldbank.org, last access: 23 April 2014, 2011.

Jongman, B., Kreibich, H., Apel, H., Barredo, J. I., Bates, P. D., Feyen, L., Gericke, A., Neal, J., Aerts, J. C. J. H., and Ward, P. J.: Comparative flood damage model assessment: towards a European approach, Nat. Hazards Earth Syst. Sci., 12, 3733-3752, doi:10.5194/nhess-12-3733-2012, 2012a.

Jongman, B., Ward, P. J., and Aerts, J. C. J. H.: Global exposure to river and coastal flooding: Long term trends and changes, Global Environ. Chang., 22, 823-835, doi:10.1016/j.gloenvcha.2012.07.004, 2012b.

Kazama, S., Sato, A., and Kawagoe, S.: Evaluating the cost of flood damage based on changes in extreme rainfall in Japan, Sustain. Sci., 4, 61-69, doi:10.1007/s11625-008-0064-y, 2009.

Kelman, I. and Spence, R.: An overview of flood actions on buildings, Eng. Geol., 73, 297-309, doi:10.1016/j.enggeo.2004.01.010, 2004.

Kreibich, H., Seifert, I., Merz, B., and Thieken, A. H.: Development of FLEMOcs - a new model for the estimation of flood losses in the commercial sector, Hydrol. Sci. J., 55, 1302-1314, doi:10.1080/02626667.2010.529815, 2010.

Kundzewicz, Z. W., Kanae, S., Seneviratne, S. I., Handmer, J., Nicholls, N., Peduzzi, P., Mechler, R., Bouwer, L. M., Arnell, N., Mach, K., Muir-Wood, R., Brakenridge, G. R., Kron, W., Benito, G., Honda, Y., Takahashi, K., and Sherstyukov, B.: Flood risk and climate change: global and regional perspectives, Hydrolog. Sci. J., 59, 1-28, doi:10.1080/02626667.2013.857411, 2013.

Lavell, A., Oppenheimer, M., Diop, C., Hess, J., Lempert, R., Li, J., Muir-Wood, R., and Myeong, S.,: Climate change: new dimensions in disaster risk, exposure, vulnerability, and resilience, in: Managing the Risks of Extreme Events and Disasters to Advance Climate Change Adaptation. A Special Report of Working Groups I and II of the Intergovernmental Panel on Climate Change (IPCC), Cambridge University Press, Cambridge, UK, and New York, NY, USA, 25-64, 2012.

Lehner, B., Döll, P., Alcamo, J., Henrichs, T., and Kaspar, F.: Estimating the Impact of global change on flood and drought risks in Europe: A continental, Integrated Analysis, Climatic Change, 75, 273-299, doi:10.1007/s10584-006-6338-4, 2006.

Merz, B., Kreibich, H., Thieken, A., and Schmidtke, R.: Estimation uncertainty of direct monetary flood damage to buildings, Nat. Hazards Earth Syst. Sci., 4, 153-163, doi:10.5194/nhess-4-1532004, 2004.

Merz, B., Kreibich, H., Schwarze, R., and Thieken, A.: Review article "Assessment of economic flood damage", Nat. Hazards Earth Syst. Sci., 10, 1697-1724, doi:10.5194/nhess-10-16972010, 2010.

Meyer, V., Becker, N., Markantonis, V., Schwarze, R., van den Bergh, J. C. J. M., Bouwer, L. M., Bubeck, P., Ciavola, P., Genovese, E., Green, C., Hallegatte, S., Kreibich, H., Lequeux, Q., Logar, I., Papyrakis, E., Pfurtscheller, C., Poussin, J., Przyluski, V., Thieken, A. H., and Viavattene, C.: Review article: Assessing the costs of natural hazards - state of the art and knowledge gaps, Nat. Hazards Earth Syst. Sci., 13, 1351-1373, doi:10.5194/nhess-13-1351-2013, 2013.

MLIT: Climate Change Adaptation Strategies to cope with Waterrelated Disasters due to Global Warming,, Ministry of Land, Infrastructure, Transport and Tourism (MLIT), Tokyo, Japan, Policy Report, 84 pp., 2008a.

MLIT: Sewerage-mitigation of inundation damage, MLIT, Tokyo, Japan, available at: http://www.mlit.go.jp/crd/sewerage/policy/ 01.html, last access: 16 October 2013, 2008b.

MLIT: Flood disaster statistics 1993-2009, MLIT, Tokyo, Japan, 2009.

MLIT: Practical Guidelines on Strategic Climate Change Adaptation Planning - Flood Disasters, MLIT, Tokyo, Japan, 58 pp., 2010. 
Morita, M.: Quantification of increased flood risk due to global climate change for urban river management planning, Water Sci. Technol., 63, 2967, doi:10.2166/wst.2011.172, 2011.

Morris, M., Bryant, R., Waller, S., Hunter, N., Lamb, R., and Crossley, A.: An Innovative Approach To Pluvial Flood Risk Assessment, Irish National Hydrology Seminar, Tullamore, Ireland, 6878, 2009.

Mouri, G., Minoshima, D., Golosov, V., Chalov, S., Seto, S., Yoshimura, K., Nakamura, S., and Oki, T.: Probability assessment of flood and sediment disasters in Japan using the Total Runoff-Integrating Pathways model, International Journal of Disaster Risk Reduction, 3, 31-43, doi:10.1016/j.ijdrr.2012.11.003, 2013.

Munich Re: Megacities - Megarisks, Trends and chalenges for insurance and risk management, Munich Re Group, Munich, Germany, 2004.

Okazawa, Y., Yeh, P. J.-F., Kanae, S., and Oki, T.: Development of a global flood risk index based on natural and socio-economic factors, Hydrolog. Sci. J., 56, 789-804, doi:10.1080/02626667.2011.583249, 2011.

Penning-Rowsell, E., Johnson, C., Tunstall, S., Tapsell, S., Morris, J., and J. C.: The benefits of flood and coastal risk management: a manual of assessment techniques, Middlesex University Press, London, UK, 2005.

Rodda, H. J. E.: The Development and Application of a Flood Risk Model for the Czech Republic, Nat. Hazards, 36, 207-220, doi:10.1007/s11069-004-4549-4, 2005.

Schmidt-Thomé, P., Greiving, S., Kallio, H., Fleischhauer, M., and Jarva, J.: Economic risk maps of floods and earthquakes for European regions, Quatern. Int., 150, 103-112, doi:10.1016/j.quaint.2006.01.024, 2006.

Seneviratne, S. I., Nicholls, N., Easterling, D., Goodess, C. M., Kanae, S., Kossin, J., Luo, Y., Marengo, J., McInnes, K., Rahimi, M., Reichstein, M., Sorteberg, A., Vera, C., and Zhang, X.: Changes in climate extremes and their impacts on the natural physical environment, in: Managing the Risks of Extreme Events and Disasters to Advance Climate Change Adaptation. A Special Report of Working Groups I and II of the Intergovernmental Panel on Climate Change (IPCC), Cambridge University Press, Cambridge, UK, and New York, NY, USA, 109-230, 2012.

Smith, D.: Flood damage estimation - A review of urban stagedamage curves and loss function, Water SA, 20, 231-238, 1994.

Smith, K.: Environmental Hazards: Assessing Risk and Reducing Disaster, 2nd Edn., Routledge, London, 1996.

Spekkers, M. H., Kok, M., Clemens, F. H. L. R., and ten Veldhuis, J. A. E.: A statistical analysis of insurance damage claims related to rainfall extremes, Hydrol. Earth Syst. Sci., 17, 913-922, doi:10.5194/hess-17-913-2013, 2013.
UNDP: Reducing disaster risk: A challenge for development, New York, USA, available at: http://www.undp.org/content/undp/en/home/librarypage/, last access: 4 May 2014, 2004.

UNISDR: 2009 UNISDR Terminology on Disaster Risk Reduction, United Nations Office for Disaster Risk Reduction (UNISDR), Geneva, Switzerland, 2009.

USGS: GTOPO30 global digital elevation model, United States Geological Survey Falls, South Dakota, EROS data centers, available at: ftp://edcftp.cr.usgs.gov/, last access: 11 November 2013, 1996.

Utsumi, N., Seto, S., Kanae, S., Maeda, E. E., and Oki, T.: Does higher surface temperature intensify extreme precipitation?, Geophys. Res. Lett., 38, L16708, doi:10.1029/2011GL048426, 2011.

Van Riel, W.: Exploratory study of pluvial flood impacts in Dutch urban areas, Deltares, Delft, The Netherlands, 2011.

Vogel, R. M.: The Probability Plot Correlation Coefficient Test for the Normal, Lognormal, and Gumbel Distributional Hypotheses, Water Resour. Res., 22, 587-590, doi:10.1029/WR022i004p00587, 1986.

Wake, B.: Flooding costs, Nature Climate Change, 3, 778-778, doi:10.1038/nclimate1997, 2013.

Ward, P. J., Jongman, B., Weiland, F. S., Bouwman, A., van Beek, R., Bierkens, M. F. P., Ligtvoet, W., and Winsemius, H. C.: Assessing flood risk at the global scale: model setup, results, and sensitivity, Environ. Res. Lett., 8, 044019, doi:10.1088/17489326/8/4/044019, 2013.

Winsemius, H. C., Van Beek, L. P. H., Jongman, B., Ward, P. J., and Bouwman, A.: A framework for global river flood risk assessments, Hydrol. Earth Syst. Sci., 17, 1871-1892, doi:10.5194/hess-17-1871-2013, 2013.

Yamamoto, H., Iwaya, K., Suzuki, K., and Hayakawa, S.: Heavy rainfall disaster in September of 1998 by Akisame Front in Kochi Prefecture, Journal of Natural Disaster Science, 18, 213-226, 1999.

Yoshimura, K., Sakimura, T., Oki, T., Kanae, S., and Seto, S.: Toward flood risk prediction: a statistical approach using a 29-year river discharge simulation over Japan, Hydrological Research Letters, 2, 22-26, doi:10.3178/HRL.2.22, 2008.

Zhou, Q., Mikkelsen, P. S., Halsnæs, K., and Arnbjerg-Nielsen, K.: Framework for economic pluvial flood risk assessment considering climate change effects and adaptation benefits, J. Hydrol., 414-415, 539-549, doi:10.1016/j.jhydrol.2011.11.031, 2012. 